\title{
MIGRANTES HAITIANOS EM SINOP/ MT: DIREITOS, TRABALHO E REDES DE SOCIABILIDADES
}

\author{
HAITIAN MIGRANTS IN SINOP / MT: RIGHTS, WORK, AND \\ SOCIABILITY NETWORKS
}

\author{
Ivone Jesus Alexandre ${ }^{1}$ \\ Everton Neves dos Santos ${ }^{2}$
}

\begin{abstract}
RESUMO: O texto aborda sobre o direito, trabalho e redes de sociabilidades de migrantes haitianos em Sinop MT. Os dados foram gerados a partir de entrevistas e conversas informais com homens e mulheres haitianas. Constatamos que tanto as mulheres quanto os homens haitianos passam por situações de trabalhos que ferem os direitos de cidadão e sua dignidade, são explorados por patrões e empresários que abusam de sua condição de migrantes em Sinop/MT. Os haitianos utilizam da igreja como um espaço de sociabilidades, lugar onde podem exercer sua religiosidade, encontrar seus pares, socializarem e se relacionar com seus conterrâneos.
\end{abstract}

PALAVRAS-CHAVE: Migrantes. Direitos. Trabalho. Rede de Sociabilidade.

ABSTRACT: The text addresses the rights, work and sociability networks of Haitian migrants in Sinop MT. The data were generated from interviews and informal conversations with Haitian men and women. We note that both Haitian women and men experience work situations that violate the rights of citizens and their dignity, are exploited by employers and entrepreneurs who abuse their condition as migrants in Sinop / MT. The Haitian use the church as a sociability space, a place where they can exercise their religiosity, meet their peers, socialize and relate to their fellow countrymen.

KEYWORDS: Migrants. Rights. Work. Sociability Network.

\footnotetext{
* Pesquisa decorrente do doutoramento desenvolvido na Universidade Federal de São CarlosUFSCAR, sem financiamento.

${ }^{1}$ Professora Adjunta na área de Metodologia de Ensino na Universidade do Estado de Mato Grosso (UNEMAT).

${ }^{2}$ Doutorando pela Universidade Federal de São Carlos-UFSCAR- do Programa de Pós em Sociologia (CAPES 6);
} 


\section{Introdução}

A migração haitiana para Sinop/MT iniciou por volta do ano de 2014, segundo a mídia local, há 200 haitianos em Sinop e $3.556 \mathrm{mil}^{3} \mathrm{em}$ todo o estado de Mato Grosso. A princípio vieram para a cidade somente haitianos adultos, ao conseguirem emprego e moradia buscam suas famílias.

Alguns migrantes ${ }^{4}$ haitianos tiveram dificuldades em se inserir no mercado de trabalho, devido à situação econômica e política do país que resultou na redução de oferta de emprego. Pesquisas com mulheres haitianas (MEJIA, CAZZAROTTO, 2017; SANTOS, FETZNER, 2019) mostram que em relação ao mercado de trabalho elas demoram em arrumar um emprego, devido à pouca escolaridade. No caso das participantes desse estudo elas acrescentaram a dificuldades com a língua, oferta de trabalho com remuneração inferior ao estabelecido no mercado e a capacidade delas em realizar uma faxina em uma casa é posta sob suspeita por algumas pessoas que contratam esse tipo de serviço (ALEXANDRE, 2019).

Os dados desse texto foram gerados através de entrevistas, depoimentos e conversas informais com os pais de crianças migrantes que participaram de uma pesquisa ${ }^{5}$ de doutorado em Sociologia na sub área Sociologia da Infância concluída em 2019. Nesse sentido, as falas apresentadas são de três casais migrantes, ou seja, três mulheres e três homens, sendo 6 pessoas migrantes do Haiti. Optamos em apresentá-los pelas iniciais de seus nomes para proteger a sua identidade.

\footnotetext{
${ }^{3}$ FONTE:https://g1.globo.com/mt/mato-grosso/noticia/2018/08/10/mt-acolheu-3556-haitianose-venezuelanos-nos-ultimos-8-anos-diz-relatorio.ghtml Acesso em 27 ago de 2019.

${ }^{4}$ " [...] o uso do termo migrante (no lugar de imigrante) e migração (no lugar de imigração) nos permite enfatizar as dimensões múltiplas tanto de movimento, trânsito e fluidez quanto de temporalidades e motivações que marcam as migrações contemporâneas e que podem variar em função de diferentes fatores políticos, econômicos e sociais" (COGO, BADET, 2013:12), no entanto, serão mantidas as citações que utilizam os termos imigrar e imigrante.

${ }^{5}$ Tese de doutorado "A presença das crianças migrantes haitianas nas escolas de Sinop /MT: o que elas visibilizam da escola?" e teve como sujeitos de pesquisa as crianças migrantes haitianas, seus pais e os professores de escolas públicas de Sinop MT. A abordagem metodológica desse estudo foi etnográfica e os dados gerados a partir de observações, entrevistas, depoimentos com todos os envolvidos. Os dados apresentados nesse texto foram coletados junto aos pais das crianças migrantes.
} 
O início da elaboração do texto foi no ano 2017 para cumprimento créditos e exigência de avaliação da disciplina de doutorado "Migração histórica". Naquele momento o enfoque artigo foi somente as redes de sociabilidades dos migrantes haitianos. No início de 2020, resolvemos retomar o texto e acrescentar a ele a discussão sobre os direitos do migrante e as políticas públicas em Mato Grosso voltadas para esses migrantes.

Assim, a tessitura do texto passa por diferentes momentos de efervescência política, entre o impedimento da presidenta Dilma Roussef ao início do governo Jair Messias Bolsonaro.

Um dos recursos utilizado para gerar os dados foi o aplicativo de whatsapp, isto porque ao encontrar os sujeitos de pesquisa ${ }^{6}$ e solicitar o contato por telefone, com o objetivo de contatar posteriormente para eventuais informações adicionais, imediatamente (o celular que possui esse aplicativo) inclui a pessoa no grupo de comunicação. Guimarães (2017: 80) defende que "os avanços dos meios de comunicação acabam por criar novas formas de agir e interagir e também faz nascer novos tipos de relacionamentos sociais e a internet passa a produzir essa nova dinâmica social". Esse foi um dos propósitos de utilizar o aplicativo whatsapp nesse estudo.

\section{Migração Haitiana para Sinop no estado de Mato Grosso}

Situado no Caribe, o Haiti ocupa uma pequena porção ocidental da ilha de Hispaniola, no arquipélago das Grandes Antilhas, que partilha com a República Dominicana (SEITENFUS, 2015). O Haiti foi a primeira nação negra livre, o povo haitiano enfrentou e venceu a batalha contra o exército de Napoleão Bonaparte, um ato impensável para uma sociedade extremamente racializada ${ }^{7}$.

\footnotetext{
${ }^{6}$ Todos os participantes assinaram o termo de consentimento que garantia a eles anonimato e autorizava a pesquisa e a divulgação dos dados relativos aos objetivos da pesquisa.

${ }^{7}$ A ideia de "racialização" ou "formação de raça" se baseia no argumento de que a raça é uma construção social e categoria não universal ou essencial da biologia. Raças não existem fora da representação. Em vez disso, elas são formadas na e pela simbolização em um processo de luta pelo poder social e político. O conceito de racialização refere-se aos casos em que as relações sociais entre as pessoas foram estruturadas pela significação de características biológicas
} 
Os haitianos cometeram o inaceitável em 1804: um crime de lesa-majestade para um mundo inquieto. O Ocidente era, na época, colonialista, escravocrata e racista. Sustentava-se com a exploração das terras conquistadas. Assim, o modelo revolucionário haitiano assustou as Grandes Potências colonialistas e racistas. Os Estados Unidos somente reconheceram a independência do Haiti em 1862 e a França exigiu pesada compensação financeira para aceitar essa libertação. Logo, a independência é comprometida e o desenvolvimento entravado. Desde então o mundo nunca soube como tratar o Haiti e resolveu ignorá-lo. Começaram os 200 anos de solidão do Haiti no cenário internacional (SEITENFUS, 2015:63).

A França não aceitou a liberdade dos ex-escravizados e impôs uma dívida exorbitante ao País, esse fato aliado às intervenções externas, incessantes governos ditadores, a invasão americana no ano 1913 e o embargo internacional fazem do país um dos mais pobres do Caribe. Assim, mesmo com a independência e o fim da escravidão, o Haiti não conseguiu fortalecer um sistema que assegurasse um projeto político e econômico a nação.

[...] condições econômicas e políticas anteriores que, durante os séculos XVIII e XIX, também contribuíram para impulsionar fluxos migratórios de haitianos, a partir da implantação, no Haiti, de um sistema econômico de plantação de cana e de café que, às custas da exploração da força de trabalho e dos recursos naturais, visou à obtenção de rentabilidade máxima em curto prazo (Audebert, 2011). A sucessão de governos ditatoriais, golpes de estado e uma guerra civil que durou vários anos contribuíram para aprofundar, nas últimas décadas, as dificuldades socioeconômicas e políticas enfrentadas pela população haitiana (COGO, 2016: s/n).

Nesse sentido, os haitianos quando migram para outros países é em função do contexto da sociedade de origem que dificulta e impossibilita a melhoria das condições de vida. No Haiti somente $20 \%$ da população haitiana está empregada resta aos demais a opção de trabalho vinculadas ao comércio de diversas mercadorias ou prestação de serviços (MEJIA, CAZAROTTO, 2018).

humanas, de tal modo a definir e construir coletividades sociais diferenciadas (SILVÉRIO; TRINIDAD, 2012:.910 - nota de rodapé $\mathrm{n}^{\circ} 11$ ). 
Diferentes motivos impulsionam os haitianos a migrarem para o Brasil, entre eles, o País ter uma população em sua maioria negra, segundo IBGE de 2010. A chegada desses imigrantes se intensificou a partir de 2011 (COGO, 2016), além de uma vida melhor eles buscam trabalho.

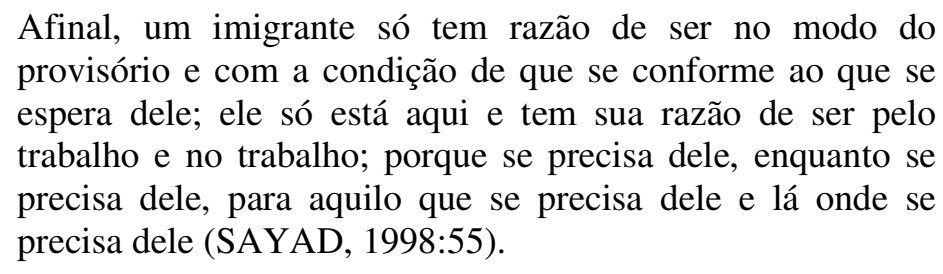

Assim, refletimos como os migrantes haitianos são recebidos no Brasil, pois são negros, pobres, de país periférico e não possuem o perfil fenotípico desejado para um país cujo histórico migratório mostra o interesse por uma migração seletiva, cujo objetivo era atingir o branqueamento da nação. Os migrantes haitianos chegam e encontram uma forma de preconceito racial muito denunciado nas pesquisas e na mídia.

[...] sobre o imigrante que chega, recai um "olhar" que o diferencia dos demais e que tenta localizá-lo nas hierarquias sociais existentes. Nesse sentido alguns imigrantes são melhor "aceitos" por suas características físicas, suas nacionalidades, suas atividades profissionais etc. (DEMARTINI, 2010:51).

Guimarães (2017) afirma que não é a maioria dos brasileiros que recebe mal os haitianos e que um conjunto da sociedade brasileira se articulou para ajudar esses migrantes, as pastorais, o Centro Scalabriniano de Estudos Migratórios, as $\mathrm{ONG}^{\prime}$ s, movimentos sociais e também parte do governo brasileiro $^{8}$ que implantou políticas regionais no Acre, São Paulo, Rio Grande do Sul e Mato Grosso, dentre outros. Algumas prefeituras, como a de Curitiba, São Paulo e Contagem têm realizado ações no sentido de pensar políticas estaduais para as escolas poderem receber as crianças migrantes.

Atualmente os registros indicam cerca de 200 haitianos morando em Sinop ${ }^{9}$, mas acreditamos que esses dados não correspondam a realidade. Há

\footnotetext{
${ }^{8}$ Governo Federal de 2010 a 2015.

${ }^{9}$ FONTE: http://www.gcnoticias.com.br/geral/vereadores-aprovam-mocao-de-aplausos-paraequipe-da-ubs-sao-cristovao/22024696. Acesso em 18 fev. de 2017.
} 
uma dificuldade em checar esses números na cidade seja pela Policia FederalPF ou pela receita federal, órgãos que fazem o cadastro de pessoa física para o migrante poder trabalhar legalmente na cidade. Essa dificuldade ocorre devido os registros de migrantes englobarem todos os haitianos moradores da comarca de Sinop, que é composta por várias cidades da região, assim, fica difícil precisar quantos migrantes haitianos são moradores somente na cidade de Sinop.

Sinop é uma cidade que tem 41 de reocupação ${ }^{10}$ e conta com uma população de 113.099 segundo o site do IBGE $^{11}$. É reconhecida nacionalmente como uma das cidades que mais se desenvolvem no estado de Mato Grosso. Situa-se no extremo norte e leva o nome da empresa responsável pelas vendas de lotes na região, a Sociedade Anônima do Norte do Paraná (SINOP). Seus espaços urbanos e a arquitetura foi planejada no modelo das cidades da região Sul do País. Pelo fato da mídia divulgar a cidade como próspera e com ótimas oportunidades de emprego, as pessoas de diferentes lugares vem para a cidade e região em busca de melhores condições de vida e de trabalho, entre eles, os migrantes do Haiti.

Os migrantes haitianos e os direitos legais e humanos

Gregori (2007:16) afirma que o enfoque do tema migrações, considerados os fatores locais de país a país, não se pode negar que os elementos básicos desse processo sejam: "globalização, pobreza, conflitos armados, instabilidade política, desenvolvimento incipiente ou insuficiente para suprir as necessidades das pessoas". No caso dos haitianos, adiciona a esses elementos os terremotos que ocorreram no país, portanto, é necessário considerarmos que as discussões sobre os migrantes não percam de vista os

\footnotetext{
${ }^{10}$ Para entender como os migrantes haitianos são recebidos em Mato Grosso, na cidade de Sinop é preciso retomar, mesmo que sucintamente, como foi o processo de reocupação do Estado. O termo reocupação é utilizado por Joanoni Neto (2014) quando afirma que esse espaço, tido como "vazios demográficos" sempre foi ocupado por sociedades indígenas, seringueiros, posseiros e comunidades quilombolas. " $\mathrm{O}$ fato de esse espaço ter sido considerado vazio, o que significou que toda a ocupação pré-existente de diferentes grupos indígenas, garimpeiros, posseiros, comunidades extrativistas e quilombolas foi ignorada para qualquer fim, o que tornou o avanço dessa nova fronteira do capital muito violento" (JOANONI NETO, 2014:187).

${ }^{11}$ FONTE: https://cidades.ibge.gov.br/brasil/mt/sinop/panorama Acesso em 27 de ago. 2018.
} 
direitos fundamentais da pessoa humana, que "passaram a ser o instrumento legítimo e aceito de concertação interna e internacional" (GREGORI, 2007:16).

O fato de ser migrante já lhe confere o estatuto de estrangeiro, de não pertencer ao local, assim, se o migrante estiver irregular, sem documentos acaba sofrendo privações, desamparo por parte do Estado, das políticas públicas destinada ao migrante e muitas vezes são desrespeitados os seus direitos econômicos, sociais e culturais. Gregori (2007) afirma que isso ocorre porque para efeitos de proteção, organizações institucionalizadas que cuida desses direitos privilegiam os casos ligados a violações de direitos civis e políticos [refugiados] em detrimento dos direitos econômicos, sociais e culturais.

Sousa (2018) menciona que os tratados internacionais que regulam os direitos humanos dos estrangeiros mudaram de forma drástica após a $2^{\mathrm{a}}$ Guerra Mundial. Segundo a autora, são eles que resumem a estrutura normativa básica dos direitos humanos regidos atualmente e podem ser destacados três grandes tratados envolvendo direitos humanos: "a Declaração Universal dos Direitos Humanos, de 1948; o Pacto Internacional sobre Direitos Civis e Políticos e o Pacto Internacional sobre Direitos Econômicos, Sociais e Culturais, ambos de 1966" (SOUSA, 2018: 23).

A pesquisadora confirma que o resumo dos direitos humanos no mundo pós-guerra reflete o consenso mundial de que o ser humano é detentor de direitos fundamentais, inerentes à sua condição, e que esses direitos precisam ser reconhecidos e respeitados para que seja assegurado a dignidade humana. Esses tratados garantem os direitos tidos como prementes a existência humana, o direito à vida, à liberdade, a não submissão à tortura e à escravidão. Sem esquecer o direito ao trabalho, à moradia, à alimentação, entre outros. Esses direitos se dividem em três tipos ou gerações: "a primeira geração, que trata de direitos relacionados à liberdade, a segunda geração, com direitos relacionados à igualdade, e a terceira geração, com direitos relacionados à fraternidade". No entanto, pelos dados expostos nesse texto, veremos que no caso dos migrantes, de origem negra e países periféricos, esses direitos na prática não são plenamente respeitados. 
Desde a promulgação da Declaração Universal dos Direitos Humanos em 1948 pela Organização das Nações Unidas (ONU) houve no plano internacional tratados, resoluções pactos e declarações de caráter ético, político e normativo (CANDAU, 2012). Os estados comprometidos buscaram adequar suas legislações para esse fim. No Brasil, a partir da Constituição Cidadã de 1988 foi incorporado a defesa e proteção dos direitos fundamentais ao ser humano, no entanto sabemos que há muitas formas de violência e usurpação dos direitos que são praticadas contra as pessoas por sua raça ${ }^{12}$, gênero e etnia.

A Convenção e Corte Interamericana de Direitos Humanos (CADH) ou também como é conhecido de "Pacto de São José da Costa Rica" é um tratado internacional entre os Estados-Membros da OEA. É composto por trinta e cinco países independentes da América, destes, vinte e cinco ratificaram a convenção. "A CADH dispõe que toda pessoa tem direitos essenciais que não derivam da condição de ser nacional de algum Estado, mas sim fundamentados nos atributos da pessoa humana" (VERAS, 2010: 606).

Segundo Veras (2010), a CADH se refere ao Direito de Migração que dispõe no artigo 22 sobre o direito a circulação e residência. $\mathrm{O}$ artigo 2 diz que toda pessoa terá o direito de sair livremente de qualquer país, inclusive de seu próprio país. $\mathrm{O}$ artigo 5 menciona que ninguém pode ser expulso do território do Estado do qual for nacional e nem ser impedido do direito de nele entrar. $\mathrm{O}$ artigo 6 diz que o estrangeiro que se encontre ilegal no território de um Estadoparte na presente Convenção, só poderá dele ser expulso em decorrência de decisão adotada em conformidade com a lei. E o artigo 9 diz que é proibido a expulsão coletiva de estrangeiros.

Para Oliveira (2017:172), o tratamento das questões relacionadas às migrações internacionais no Brasil tem momentos de paralisia e retrocessos e exemplifica citando Marinucci (2012) que discorre sobre quando o Brasil não assinou da Convenção 97 das Nações Unidas, sobre o direito dos trabalhadores migrantes e suas famílias. Para Marinucci (2012), isso configura a "não política

\footnotetext{
${ }^{12} \mathrm{O}$ termo raça nesse texto é utilizado como um conceito sociológico
} 
migratória”, ou seja, seria a manutenção das possíveis práticas herdadas do regime de exceção.

Oliveira (2017) descreve que em 24 de maio do ano de 2017, o presidente da República sancionou a nova lei de migração, a Lei n. 13.445/2017 (BRASIL, 2017) com 20 vetos. Na opinião do pesquisador, os vetos que causaram maiores prejuízos foram os propostos pela Casa Civil e Ministério da Justiça e Segurança Pública:

Casa Civil, que logo no Inciso I do $\S 1^{\circ}$ do art. $1^{\circ}$ vetou a definição de migrante sob o argumento de que o conceito estava demasiadamente amplo ao incluir o imigrante, o emigrante, o residente fronteiriço e o apátrida. Também vetou o parágrafo $4^{\circ}$ do art. 113 , que colocava como grupo vulnerável a pessoa que responde em liberdade por algum delito cometido. Esses vetos revelam, por um lado, a falta de conhecimento das várias dimensões da mobilidade humana e, por outro, a insensibilidade ao não reconhecer que uma pessoa que responde por processo criminal num país estranho, seja qual for o motivo, encontra-se em enorme vulnerabilidade. $\mathrm{O}$ atenuante a favor da necessária aprovação do dispositivo reside no fato de a pessoa estar em liberdade, o que sinaliza tratar-se de delito de menor poder ofensivo;

- Ministério da Justiça e Segurança Pública, Advocacia Geral da União e do Gabinete de Segurança Institucional, de onde partiram vetos igualmente prejudiciais, como: o que não garante a livre circulação aos povos originários, alegando afronta à soberania nacional; o que impede a revogação das expulsões decretadas antes de 1988, ou seja, aquelas baseadas no regime de exceção, também sob o argumento que isso afetaria a soberania nacional; o que ampliava a autorização de trabalho, sem a necessidade de autorização específica, cuja justificativa foi a necessária referência específica via norma; e o veto integral ao artigo que concedia anistia aos migrantes em situação irregular que tivessem ingressado no território nacional até julho de 2016. A justificativa dada é muito frágil, uma vez que se ampara no fato de existirem diversos status migratórios que seriam beneficiados e por não ser possível precisar a data de entrada da pessoa em situação irregular (OLIVEIRA, 2017:176).

De acordo com Oliveira (2017), o ponto positivo foi o término do anacronismo do Estatuto dos Estrangeiros, aparato jurídico inspirado no regime de exceção, que tinha por premissa ideológica a doutrina da segurança nacional e que prevalecia mesmo após a aprovação da Constituição de 1988, que, entre 
outros seus objetivos, colocava como missão sepultar os resquícios jurídicos da ditadura militar.

\begin{abstract}
[...], o país passa a ter uma das legislações mais modernas no trato das políticas migratórias, avançando no tratamento dos pilares que sustentam a integração plena do migrante à sociedade brasileira ao assegurar o pleno acesso aos serviços, garantindo a reunião familiar, reconhecendo a formação acadêmica obtida no exterior, permitindo a associação sindical e política, facilitando a inclusão laboral, repudiando práticas de discriminação e descriminalizando a migração e repudiando práticas de deportações coletivas (OLIVEIRA, 2017:174).
\end{abstract}

Houve avanço no enfoque do novo marco legal das migrações, com foco na garantia dos direitos das pessoas migrantes que vivem em outro país quanto aqueles brasileiros que se mudam do Brasil.

Há muitos anos se esperava essa nova lei de migração, pois a existente dificultava a cidadania plena dos migrantes no país de adoção. Com a nova lei evita ou pelo menos dificulta serem explorados por serem estrangeiros. Logo que chegaram em Sinop alguns migrantes denunciaram junto a OAB da cidade, abusos trabalhistas ${ }^{13}$ de alguns empresários tais como condições de moradia e falta de assistência médica aos trabalhadores, etc.

Migrantes haitianos em Sinop - adaptação, redes de sociabilidades, condições de moradia e de trabalho

Com base nos depoimentos dos migrantes haitianos, entendemos que é pelo trabalho que estão em Sinop, é pelo emprego que vislumbram adquirir aqui e que não conseguiram no Haiti, ou seja, uma vida digna para a sua família. Essa busca de ter um emprego faz com que se desloquem para longe de seus parentes, de seus entes familiares, de sua terra de origem. As falas dos pesquisados demonstraram saudosismo de sua terra natal.

Os migrantes haitianos geralmente são empregados no setor agropecuário (indústria de carne), construção civil, setores metalúrgico, têxtil, hoteleiro e de serviços de limpeza. (XIMENES, 2016). Em Sinop, esses

\footnotetext{
${ }^{13}$ FONTE: $\quad$ https://www.sonoticias.com.br/geral/sinop-haitianos-reclamam-de-exploracaotrabalhista-e-mas-condicoes-de-vida/ . Acesso em out. de 2017.
} 
migrantes são vistos nos postos de trabalho do setor de alimentação, rede de hotelaria, na Usina Hidrelétrica de Sinop e na construção civil. Assim, os postos de trabalho que os migrantes participantes dessa pesquisa mais ocupam são como cozinheiras, garçons, auxiliar de pedreiro.

Como foi mencionado anteriormente, as mulheres pesquisadas demoraram mais para adentrar o mercado de trabalho, no entanto, a Sra. I. J., sujeito dessa pesquisa, foi exceção porque ela veio primeiro para o Brasil e não o esposo. Em sua trajetória de migração ela passou pelo abrigo do Acre e foi morar na cidade de Malau ao Sul do País, porém não se adaptou ao frio e foi para Manaus, devido à dificuldade em arrumar trabalho nessa cidade resolveu vir para Sinop onde tinha "parentes ${ }^{14 \% "}$.

Em Sinop, a migração dos haitianos ocorre em uma configuração assim definida: geralmente vem um membro da família, que pode ser o pai ou a mãe ${ }^{15}$, arrumam emprego e depois vem os "parentes", que podem ser os filhos, os tios, irmão e até amigos "chegados", isto é, não tem laços consanguíneos. Trazer a família e parentes produz a migração em cadeia, no caso de haitianos ocorre para diferentes países, entre eles o Brasil. Para os que estão em busca ou processo de migração a ajuda dos que já estão estabelecidos no país de adoção é fundamental, e caracteriza as redes de ajuda ou auxílio. Essa mensagem de Sra. I.J. enviada, via whatsapp, para um dos pesquisadores por ocasião do cancelamento $^{16}$ de uma entrevista mostra bem essa preocupação e a existência dessa rede de ajuda.

\footnotetext{
${ }^{14}$ Para ser 'parente' (fanmi) no sentido amplo, ou seja, não só consanguíneo, mas também amigo ou vizinho, é importante um esforço constante na manutenção de laços de troca e parentalidade, como visitar casas de outras pessoas. Uma visita implica sentar-se por um tempo, conversar, contar histórias, ouvir e comentar notícias de rádio, levar presentes e 'comer junto'. A noção de 'comer junto' (manje ansanm) é também uma categoria sociológica de classificação de pessoas e grupos: aqueles com quem 'se come junto' são parentes, amigos e vizinhos; aqueles com quem 'não se come junto' são pessoas a serem evitadas, inimigas e suspeitas do uso de feitiçaria. (BULAMAH, 2015, p.85).

${ }^{15}$ Depoimento dado à pesquisadora dia 10 ago. de 2016.

${ }^{16} \mathrm{O}$ cancelamento da entrevista se deu pela chegada dos parentes, ou seja, novos migrantes e a busca por documentação no país. Assim que chegam a cidade que escolheram para morar buscam providenciar e isso é uma prioridade para os migrantes haitianos. Foi esse o motivo da mensagem. É oportuno relatar que o fato de ter ocorrido vários encontros para entrevistas e depoimentos, as relações transcenderam a relação sujeito e pesquisador.
} 
- "To esperando o ônibus para levar a minha família no correio por coisa do CPF".

Um dos autores perguntou a ela:

- "Chegaram mais crianças haitianas para estudar na escola?

Ela respondeu:

- "Não. Tudo adulto." (Áudio via whatsapp dia 14 dez. de 2016).

Esses parentes, no primeiro momento ficam alojados em uma só casa, recebem ajuda como alimento e pouso, além de informações sobre oportunidades de empregos até que consigam adentrar o mercado de trabalho. Truzzi (2008, p. 203) exemplifica os conceitos de "cadeia" ou "redes migratórias" que definem o grau de investimento para a vinda dos imigrantes: “[...] Estes podiam prover tanto informações, no tocante às perspectivas de emprego e alojamento iniciais, como recursos, por meio de remessas monetárias, que pudessem financiar e assim viabilizar a viagem" (TRUZZI, 2008: 203 - grifos do autor).

São os migrantes que possuem emprego, estabelecidos na cidade e com residência fixa na sociedade receptora, que informam os conterrâneos no país de origem, sobre as possibilidades de vir, o momento adequado e muitas vezes auxiliam com dinheiro para poder trazer os demais membros da família, "parentes" e amigos que podem estar passando por dificuldades financeiras no Haiti ou mesmo amigos que tomam dinheiro emprestado para poder migrar para o Brasil. "Os recém-chegados ainda devem dividir o salário recebido entre o montante destinado ao seu sustento, remessas para a família e o pagamento da dívida contraída” (XIMENES, 2016:31).

Outro aspecto importante relatado pelos migrantes haitianos é sobre o que se diz do país que se quer migrar. As possíveis oportunidades ou mesmo dificuldades que podem ter na chegada ao país que os acolhe, nesse caso, o Brasil. Oswaldo Truzzi (2008) ao discutir redes de sociabilidades de migrantes reflete,

Nesse mesmo sentido, outro ponto importante é a confiabilidade atribuída a tais informações, o que enfatiza a importância das chamadas relações sociais primárias. A pessoa ou a família que pensava em emigrar tendia a confiar 
mais nas informações fornecidas, ao vivo ou por carta, por um parente, vizinho ou amigo, por exemplo, do que nos folhetos de propaganda distribuídos por um agente recrutador, cujos lucros dependiam apenas do número de indivíduos que conseguisse colocar a bordo de um vapor. Assim, os contatos pessoais tornavam-se mais importantes, porque mais confiáveis do que as informações não pessoais (TRUZZI, 2008: 206).

No caso dos primeiros migrantes haitianos, muitos dos que chegaram não tiveram esse tipo de informações quando vieram para o Brasil (XIMENES, 2014). Agora os que estão migrando informam seus "parentes" para orientar como proceder na hora de vir para o País. A tecnologia também tem auxiliado esse tipo de rede, ajuda a amenizar a distância, a se comunicarem com as suas famílias e aqueles que pretendem migrar (ZAMBERLAM, at al, 2017).

As redes sociais e aplicativos whatsapp são as formas de comunicação usadas pelos migrantes. Mesmo que muitos deles não tenham internet, costumam ficar próximos a locais que tenham sinais de wi-fi, por exemplo, bancos corporativos, lanchonetes, restaurantes e mesmo locais públicos que disponibilizam esse serviço gratuitamente. Abaixo reproduzimos um áudio de um de nossos sujeitos da pesquisa, agradecendo uma geladeira que ganhou de uma doação realizada por intermédio dos pesquisadores usando esse tipo de sinal disponível.

Boa tarde! Tudo bem? [...] tá bom, eu tudo bem graças a deus. Eu vou deixar voz pra você pra agradecer muito a senhoras e a todos pessoas que vem levar o geladeira pra mim. A dona dela de levar pra mim também, eu agradeço todos. Só a Deus, que pode resolver as coisas não é eu. Mas só quero agradecer mesmo, agradeço, agradeço, muito [...] Que deus te abençoe muito sua vida, suas famílias. Estou aqui na cidade, estou esperando ônibus pra chegar lá em casa. Estou saindo agora do meu serviço. Mas quando eu cheguei em casa eu não (risos) vou mais ter internet pra conversar com a senhora. Eu tô aqui a falar. Tem uma wi-fi lá na praça e eu uso pra deixar uma voz pra senhora pra agradecer muito [...]. Muito obrigada [...]. Que Deus a abençoe, tchau (Áudio via whatsApp no dia 05 de fev. 2017).

Este depoimento mostra também as dificuldades financeiras enfrentadas pelos migrantes haitianos em Sinop, no entanto, eles informaram que são 
agradecidos por estarem no Brasil, apesar dos empecilhos econômicos e saudades dos parentes que ficaram no Haiti, aqui é ainda é melhor do que a que tinham em seu país de origem.

As redes de sociabilidades da qual os haitianos fazem parte é a sua casa, a escola e a igreja que optaram por frequentar. Eles gostam muito de reuniões em suas casas, chegam a juntar mais de vinte pessoas em almoços ou jantares que eles denominam de "junta panela" "17 É nesse momento que exercitam sua língua, trocam memórias, realizam sua cultura e ampliam suas relações afetivas.

Nesse texto, o enfoque é a igreja, a escolaridade, as condições de moradia e as relações de trabalho. Os sujeitos que entrevistamos frequentam a igreja evangélica Batista e a Assembleia de Deus Filadélfia. Aliás não conhecemos nenhum haitiano que não fosse evangélico. Magalhães (2017) observou fato semelhante em sua pesquisa.

Embora o vodu seja mais que uma religião, uma instituição social e cultural haitiana, de forte conteúdo pedagógico, místico e de pacificação social (SEITENFUS, 2016), no grupo analisado a religião predominante é a evangélica, superior também em relação à Católica (MAGALHÃES, 2017:166).

A Igreja da Assembléia de Deus Filadélfia fica em um bairro centralizado, e no período da coleta dos dados era em um local pequeno e bem humilde, atualmente essa igreja mudou para um prédio maior. Presenciamos um culto que foi todo pronunciado em língua Kreyòle ${ }^{18}$ e realizado por pastores haitianos. Nesse dia, a igreja estava cheia de migrantes haitianos, alguns ficaram em pé, outros ajoelhados, outros sentados em cadeiras e outros encostavam o rosto junto a parede. Observamos que os migrantes faziam as orações com muita emoção, ardor e alguns deles tinham lágrimas nos olhos, a “[...] manutenção da língua materna, no quotidiano familiar [...], era uma das maneiras de manter a cultura e as vinculações com a sociedade de origem, além de permitir a comunicação entre os próprios imigrantes, bem como a coesão do

\footnotetext{
${ }^{17}$ É quando se reúnem em uma casa de um dos migrantes e todos levam um prato de alimento e todos conversam, fazem orações e depois se alimentam.

${ }^{18}$ Kreyòlé é o idioma falado por mais de $90 \%$ da população haitiana, foi reconhecido como segundo idioma oficial do Haiti em 1986 (ROSA, 2006).
} 
grupo" (DEMARTINI, 2004:223). Nesse caso, a igreja é um espaço que a língua de origem contribui para a manutenção da sua identidade étnica.

A igreja é ponto de encontro dos haitianos, nesse caso, especificamente a igreja conhecida como dos haitianos, no entanto, a igreja pertence ao pastor e sua esposa, eles são brasileiros e nos disseram que permitiam que e os migrantes usassem a igreja para seus cultos. A esposa do pastor também é pastora, no dia que fizemos observação ela participou do culto fazendo avisos e orientações sobre os cuidados com a igreja, preparativos para o culto e orientação para os haitianos na recepção dos "irmãos" da igreja. Ela falou em língua portuguesa porque não sabia falar na língua Kreyòle. O casal de pastores nos informou que oferece cesta básica para os haitianos e que os migrantes são pessoas muito honestas e trabalhadoras.

A igreja constitui uma rede de sociabilidade para os migrantes, permite exercitar a língua e manter seus vínculos com seus conterrâneos, e sem sombra de dúvida, uma rede de relacionamentos que oferece e fornece apoio considerável na fase inicial de adaptação na sociedade de recepção (TRUZZI, 2016). Os haitianos costumam levar seus filhos para o culto. "Os cultos de sábado e de domingo fazem com que a religião seja, no rol das atividades de sociabilidade, a principal atuação realizada nos finais de semana [...]" (MAGALHÃES, 2017:203). Pelas entrevistas e depoimentos concedidos, os haitianos deixam claro que é muito importante que seus filhos cresçam nos preceitos da igreja evangélica.

Os haitianos pesquisados nos informaram que iam as igrejas todos os domingos, somente uma das participantes, a Sra. I. J., disse que não podia ir em função de seu trabalho no hotel, ela era arrumadeira e sua folga não acontecia em um dia específico. Em relação ao trabalho que fazia nesse hotel, ela nos contou que a dona costumava pagar seu salário a cada dois meses e as vezes parcelava o pagamento do seu salário em até duas vezes ${ }^{19}$. Isso prejudicava sua vida, pois como atrasava para pagar o aluguel o proprietário da casa cobrava

${ }^{19}$ Entrevista concedida aos pesquisadores em 19 abr. de 2016 
juros, a solução dela foi se mudar para uma casa cujo aluguel era um pouco mais caro, mas que o dono não cobrava juros por atraso no pagamento.

Outro caso de abuso dos empregadores para com os migrantes foi relatado pelo Sr. B.S., ele me disse que ia embora de $\operatorname{Sinop}^{20}$ para o Sul do país porque a cidade não foi boa para eles.

A mulher (Sra. A.B.) não consegue emprego, eu demorei para achar. E trabalhei dois meses de pedreiro e o homem que contratou não me pagou. Não posso comprar alimento, honrar aluguel, por isso estou voltando para Porto Alegre. Estou há dois anos no Brasil e morava em Porto Alegre, depois veio para Sinop, deixei parentes lá. Sua esposa e filha vieram quando ele veio para Sinop, mas, aqui foi difícil achar trabalho e a esposa e o cunhado, por isso resolveram voltar para Porto Alegre.

Estranhamos sobre a situação trabalhista mencionada pelo Sr. B.S. porque o setor de construção civil em Sinop é um dos setores mais demandados, qualquer atividade ligada carece de profissionais e isso supõe salários em dia, por isso entendemos que os atrasos são situações de exploração pela condição de migrantes.

Esse fato permite comparar com o que a pesquisadora Ximenes (2016) diz em seu texto, que os haitianos se tornam mais suscetíveis a violações de direitos humanos, com trabalho em condições precárias, insalubres e algumas em condição análogas à de escravos. A maioria dos entrevistados reclamou do atraso de salário ou quando não, do seu parcelamento pelos empregadores. Eles sabem que estão tentando explorá-los, mas não se abnegam a isso:

A concentração de trabalhadores estrangeiros em geral, e haitianos em particular, em setores mais precários do mercado de trabalho formal no Brasil atesta, em realidade, não apenas as estratégias clássicas de utilização do trabalho imigrante para um emprego sub-remunerado, mas ainda pelo menos três formas de emprego de haitianos para superexploração desta força de trabalho (BAENNINGER; PERES, 2017:199).

\footnotetext{
${ }^{20}$ Fui avisada por telefone pela professora da filha desse senhor (Depoimento informal ocorrida no dia 22 set. de 2016). Descobrimos que na verdade esse senhor ia migrar para os Estados Unidos, mas para nós contou que iria voltar para o Sul.
} 
Os haitianos não são alienados, eles têm plena ciência das intenções dos patrões que querem se aproveitar da situação de serem estrangeiros, mas como são migrantes preferem adotar diferentes estratégias para lidar com essas situações, entre elas buscar o diálogo e não ir para o embate. Essa consciência tem a ver com a própria história dos haitianos que recusou a racialização nas relações de trabalho quando a França tentou construir o negro colonial (ROSA, 2010).

Foram as situações de abusos relatadas por muitos migrantes e a intensificação da migração internacional no Brasil que forçou a revisão da lei de migração. Essas relações de trabalho abusivas evidenciaram que a lei estava ultrapassada em relação aos direitos aos migrantes e foi isso que forçou a revisão da Lei da Migração no país que e foi aprovada em 24 de maio de 2017, sob o número 13.445/2017 (BRASIL, 2017).

Sobre o episódio que ocorreu com o migrante Sr. B.S., no dia 29 de setembro de 2016 no período da tarde, recebemos um whatsapp da professora de sua filha dizendo que a menina tinha ido para a escola e que a família tinha desistido de se mudar de Sinop.

Perguntamos a ela:

-Como assim não foram embora?

Ela respondeu:

-Ele (o pai) me disse que os amigos convenceram eles a ficar e por causa da igreja. Ele me disse que aqui tem a igreja né! E ai eles foram atrás para que agência de ônibus devolvesse o dinheiro. A agência devolveu $25 \%$ do dinheiro das passagens. A professora informou também que eles tinham vendido tudo e que eles agora estão na casa de um amigo (Diário de campo dia 29 set. de 2016).

O pastor da igreja que eles frequentavam aconselhou o Sr. B.S. para que não fosse embora com a família, porque na verdade não era para o Sul que planejavam ir e sim para os Estados Unidos e lá a situação estava difícil para os migrantes após medidas adotadas pelo governo em relação a chegada de novos migrantes. E que eles iriam correr riscos, porque planejavam atravessar a fronteira clandestinamente em um barco ${ }^{21}$ e isso era muito perigoso.

\footnotetext{
${ }^{21}$ Diário de campo do dia 24 out. de 2016.
} 
Essa situação reflete a crise política e econômica que o Brasil vem atravessando e que influencia no desejo de alguns migrantes em querer migrar internamente ou buscar outro país que lhes ofereçam melhores condições e oportunidades de trabalho.

Especialmente após meados de 2016, o crescimento do desemprego em cidades do sul e do sudeste do Brasil tem condicionado pelo menos três movimentos na dinâmica migratória haitiana no Brasil: um movimento de ida ou mesmo de retorno de imigrantes haitianos desempregados para a cidade de São Paulo, identificado como um espaço com melhores estruturas públicas de acolhimento e de acompanhamento; um movimento de retorno de imigrantes haitianos para o Haiti e um movimento, por fim, de ida a outros países, como Chile, Colômbia e Estados Unidos (MAGALHÃES, 2017: 255).

É o exemplo do Sr. B. S., depois de vir para Sinop/MT., ter essas experiências trabalhistas, de insucesso em arrumar um trabalho e exploração (trabalhar e demorar para receber o salário) por parte de patrões, tenta ir para os Estados Unidos pondo em risco a própria vida e de sua família. Esse fato demonstra também a insistência do migrante de um dia melhorar de vida.

O comportamento dos haitianos são sempre os mesmos nos lugares que frequentam. Seja no trabalho, na igreja ou na escola assumem uma atitude amável, sorridentes, simpáticos com todos, no entanto, essas atitudes não configuram submissão, são altivos, falantes e sabem se impor quando é preciso.

Todas essas especificações pelas quais se define e identifica o imigrante [...]. Política e polidez, e sem dúvida mais polidez do que política exigem semelhante neutralidade, que é também chamada de "obrigação de ser reservado": a forma de polidez que o estrangeiro deve adotar, e que ele se sente na obrigação de adotar-e, no limite, ele só deve adotar essa polidez porque se sente obrigado a adotá-la -, constitui uma dessas malicias sociais (ou malicia social) pelas quais são impostos imperativos políticos e consegue se a submissão a esses imperativos (SAYAD, 1998:57).

Silva (2017) afirma que é devido à falta de políticas públicas de acolhimento que atendam migrantes, principalmente aqueles em situação de vulnerabilidade social, que não tem apoio da nenhuma rede, familiar ou de 
amizade, a parceria público-privada surge como uma saída. Contudo, segundo o pesquisador tais políticas não inexistem,

[...] o ônus da acolhida recai sobre igrejas e organizações não governamentais que, apesar de todo esforço e dedicação, acabam fazendo o papel de mediadoras entre o mercado de trabalho e os imigrantes, tentando "disciplinar" a relação entre capital e trabalho. Um exemplo disso é o que se faz na Missão Paz em São Paulo, onde os empregadores que lá vão contratar algum trabalhador (a) devem assinar um "termo de conduta", comprometendo-se a cumprir a legislação trabalhista brasileira, o que nem sempre acontece. Do imigrante espera-se que ele aprenda alguns códigos culturais e tenha algum domínio da língua portuguesa para comunicarse com o novo contexto (SILVA, 2017:109).

Aqui em Sinop, as pastorais da igreja católica ofereceram cursos de língua portuguesa e também mantimentos para os migrantes. O Instituto Federal ofereceu um curso de língua portuguesa para facilitar o trabalho e a sua interação social. Não identificamos nenhuma ação das Universidades de Ensino Superior da cidade tendo como público alvo esses migrantes.

Muitas pessoas da cidade que se relacionam com os haitianos acham que eles falam francês. Alguns haitianos perceberam nisso um certo status e por isso muitos afirmam dominar o idioma francês, mas não é verdade ${ }^{22}$. A maioria dos haitianos contatados pelos pesquisadores não tinha o grau de ensino que no Brasil corresponde ao ensino médio. Sobre a escolaridade dos haitianos vejam o que fala a Ximenes (2016: 32):

Outra mudança se dá no nível de escolaridade dos migrantes. No primeiro momento, entre 2010 e 2011, metade dos estrangeiros possuía nível superior. Vieram de Porto Príncipe professores, engenheiros e enfermeiros. Depois de 2011, essa característica foi mudando, com a presença de camponeses vindos do interior. "Esse imigrante com menor escolaridade se torna ainda mais vulnerável. Fazer o diagnóstico social deles é fundamental para saber de quem estamos falando, porque isso interfere diretamente nos postos de trabalho que vão ocupar e na proteção que o Estado vai oferecer".

A condição educacional dos migrantes haitianos não faz muita diferença na cidade de Sinop. Uma haitiana ${ }^{23}$, com formação em curso de Técnico em

\footnotetext{
${ }^{22}$ Depoimento concedido em 27 ago. de 2016.

${ }^{23}$ Essa migrante não participou da pesquisa, mas nos deu esse depoimento informalmente.
} 
Laboratório no Haiti, nos contou que tinha essa profissão e que não queria trabalhar de empregada doméstica ou faxineira, e, que por isso foi criticada pelos professores da escola de sua filha, falaram que ela era orgulhosa. Essa mulher tinha condições econômicas favoráveis devido o marido ter três empregos $^{24}$, e ela contou que não queria se submeter ao trabalho faxineira e que em Sinop as propostas para ela foram somente desse tipo de serviço. Depois de algum tempo essa família se mudou para os Estados Unidos, no período ainda era o governo do Barack Obama e isso foi antes de ele pronunciar que não iria mais receber migrantes no país.

Muitas das situações relatadas pelos migrantes demonstram que em Sinop eles são percebidos como subalternos, por alguns empregadores, ser do Haiti parece condição para aceitarem qualquer tipo de atividade, remuneração abaixo do mercado e se submeter a qualquer situação de trabalho.

\section{Considerações finais}

$\mathrm{Na}$ fase de adaptação na cidade que os recebe, os haitianos convivem em suas redes de sociabilidades. Mesmo que esporadicamente ela é fundamental para o processo de inserção social e amparo afetivo. A distância da pátria e da família dificulta a vida do migrante no país que adotou para morar.

A igreja e a escola contribuem para formar redes que ampliam e solidificam os laços com seus pares e enquanto grupo, permite superar seus problemas e juntos enfrentarem a crise financeira, política e o racismo que os atinge diretamente por serem migrantes negros, pobres e vindos de uma país devastado como o Haiti.

Aqui enfrentam situações de exploração do trabalho que lhes tiram a dignidade e garantia de seu sustento, tanto dos familiares que estão aqui ou mesmo dos parentes que estão no Haiti, pois, a maioria tem filhos e ou parentes em situação precária e que precisam de ajuda financeira. Muitos empresários e patrões aproveitam de condição de migrante para atrasar salários, parcelar, ou

${ }^{24}$ Depoimento concedido em 04 mai. de 2016. 
mesmo não pagamento os seus direitos, negando a eles os que lhes é de direito, condições de trabalho e a remuneração em dia.

Os direitos adquiridos como cidadão, com direito a carteira assinada, saúde e educação são ofertas que em seu país de origem eram de difícil acesso, assim, apesar dos percalços, os migrantes afirmam que o Brasil proporcionou uma vida melhor, bens que no Haiti não tinham. Assim, migrar em qualquer contexto ainda é uma perspectiva que garante melhores condições de vida.

A maioria dos pesquisados disse que não queria estar em um lugar tão distante de seu país de origem. Lágrimas perpassam seus olhos quando se reportam ao Haiti. Esses migrantes sentiram muito a mudança política por que passa o Brasil, mesmo com muito receio de falar na política brasileira, um deles nos disse na ocasião de uma entrevista: "- Precisamos de um fora Temer! ". O impedimento que sofreu a presidente da república afetou a todos os brasileiros e também a eles. Passamos a viver um retrocesso de políticas públicas, dos direitos adquiridos e da retomada do conservadorismo que se consolidou no Brasil.

\section{Referências}

ALEXANDRE, Ivone Jesus. A presença das crianças migrantes haitianas nas escolas de SINOP/ MT: o que elas visibilizam da escola? Tese de doutorado (Doutorado em Sociologia). Centro de Educação e Ciências Humanas. Programa de Pós - Graduação em Ciências Humanas. Universidade Federal de São Carlos. São Carlos (SP), 2019.

BULAMAH, Rodrigo Charafeddine. Um lugar para os espíritos: os sentidos do movimento desde um povoado haitiano. Cadernos Pagu (45), jul.-dez., 2015. p.79-110.

CANDAU, Vera Maria. Ferrão. Direito à educação, Diversidade e Educação em Direitos Humanos. Educação \& Soc. Campinas, v.33, n.120, 2012, p-715-726.

COGO, Denise. Entre a fuga e a invasão: alteridade e cidadania da imigração haitiana na mídia brasileira. Rev Famecos (Online). Porto Alegre, v. 23, n. 1, janeiro, fevereiro, março e abril de 2016.

COGO, Denise Maria; SOUZA, Maria Badet. Guia das migrações transnacionais e diversidade cultural para comunicadores - Migrantes no Brasil. Bellaterra: Instituto Humaitas; Unisinos; Instituto de la Comunicación 
de la UAB, 2013. (Coleção: Guias De Diversidade Cultural Para Comunicadores).

DEMARTINI, Zeila de Brito F. Imigrantes: entre políticas, conflitos e preconceitos. Cadernos Ceru, v. 21, n. 2, 03, 2011, p.49- 75.

GREGORI, José. Refugiados e imigrantes: uma abordagem de direitos humanos, In. GREGORI, José. et al. (Orgs). Cadernos de debate 2. Refúgio, Migração e Cidadania. ACUR. 2007, p.15-28.

GUIMARÃES, Maristela Abadia. O "eu" confronta o "outro": o que (re) velam as manifestações de brasileiros sobre haitianos nas mídias e Redes sociais digitais. Tese (Doutorado em Educação). Programa de Pós-Graduação em Educação. Universidade Federal de Mato Grosso. CUIABÁ, MT, 2017.

INSTITUTO BRASILEIRO DE GEOGRAFIA E ESTATÍSTICA. Censo Demográfico 2010. Resultados Gerais da Amostra. Rio de Janeiro: IBGE, 2010, p.1-239.

JOANONI NETO, Vitale. Amazônia na década de 1970. A fronteira sob o olhar do migrante. Revista Eletrônica da ANPHLAC, Jan/Jul. 2014, p.186-206.

MAGALHÃES, Luís Felipe Aires. A imigração haitiana em Santa Catarina: perfil sociodemográfico do fluxo, contradições da inserção laboral $e$ dependência de remessas no Haiti. Tese (Doutorado em Filosofia e Ciências Humanas). Programa de Pós-graduação em Filosofia e Ciências Humanas. Universidade Estadual de Campinas - Campinas, SP, 2017.

MEJIA, Margarita Rosa Garviria.; CAZAROTTO, Rosmari Terezinha. O papel das mulheres imigrantes na família transnacional que mobiliza a migração haitiana no Brasil. Repocs, v.14, n.27, jan/jun. 2017, p172-190.

OLIVEIRA, Antonio Tadeu Ribeiro de. Nova Lei da Migração: avanços, desafios e ameaças. $R$. bras. Est. Pop., Belo Horizonte, v.34, n.1, jan./abr. 2017, p.172-179.

SANTOS, Mylena Francielli.; FETZNER, Andréa Pellegrini. Mulheres migrantes: invisibilidade no processo migratório e dificuldade de inserção no mercado de trabalho decente brasileiro. Anais do XVI Seminário Internacional. Demandas Sociais e Políticas públicas na sociedade contemporânea. Disponível em https://online.unisc.br/acadnet/anais/index.php/sidspp/article/view/19583/0 . Acesso em 19 ago.2020.

SAYAD, Abdelmalek. Imigração ou os paradoxos da identidade. Edusp, 1998. SEITENFUS, Ricardo. O buraco negro da consciência ocidental. Letras de Hoje, Porto Alegre, v. 50, n. esp. (supl.), dez., 2015, p. 62-75. 
SILVA, Sidney Antonio da. Imigração e redes de acolhimento: o caso dos haitianos no Brasil R. bras. Est. Pop., Belo Horizonte, v.34, n.1, jan./abr. 2017, p. 99-117.

SILVÉRIO, Valter Roberto; TRINIDAD, Cristina Teodoro. Há algo novo a se dizer sobre as relações raciais no Brasil contemporâneo? Revista Educação e Sociedade. Campinas, v. 33, n. 120, p. 891- 914, jul-set., 2012. Disponível: http://www.scielo.br/pdf/es/v33n120/13.pdf. Acesso: 08/01/2016.

SOUSA, Marilia Reato Silva de. Imigração e direitos humanos - legislação e políticas públicas - reflexos nas serventias extrajudiciais. Revista de Movimentos Sociais e Conflitos. Salvador, v. 4, n. 1. Jan/jun. 2018, p. $22-42$.

TRUZZI, Oswaldo. Redes em processos migratórios. Tempo Social, revista de sociologia da USP, v. 20, n. 1, 2008, p.199-218. (http://www.scielo.br/pdf/ts/v20n1/a10v20n1)-Acesso em 26/05/2017.

VERAS, Nathália Santos. Direitos humanos dos migrantes na jurisprudência consultiva da corte interamericana de direitos humanos. Textos \& Debates, Boa Vista, n.18, jan./jun. 2010, p. $251-268$.

XIMENES, Dimas; ALMEIDA, Guilherme. Brasil de volta ao imaginário de imigrantes. Labor-Revista do Ministério Público do Trabalho. V. II, n. 5, 2014, p. 26-32.

Recebido em: 26 de maio de 2020

Aceito em: 18 de agosto de 2020 